\title{
Emergence and verification of supercentenarians in Spain
}

\author{
Rosa Gómez-Redondo ${ }^{1}$ and Juan M. García González ${ }^{2}$ \\ 1 Universidad Nacional de Educación a Distancia (UNED), Faculty of \\ Political Sciences and Sociology, Madrid, Spain. \\ E-Mail: rgomez@poli.uned.es \\ ${ }^{2}$ Universidad Nacional de Educación a Distancia (UNED), Faculty of \\ Political Sciences and Sociology, Madrid, Spain. \\ E-Mail: jmgarcia@bec.uned.es
}

\begin{abstract}
During the final decades of the 20th century, there was a small group of people in Spain who reached very advanced ages. This was a phenomenon with no historical precedent in Spain. Despite their importance, the supercentenarians' mortality has not been well defined. To help fill this gap, our work examines the insufficiency of, and errors in, the data used to validate the alleged ages at death of this extremely old Southern European population. We have studied the ages of people who are said to have lived beyond their 110th birthdays, and who died between January 1987 and April 2007. We started with a list of 191 potential supercentenarians. But, after a meticulous process of verification of their ages, we finally validated 28 genuine supercentenarians. In three of these validated cases, the ages of the people studied exceeded 114 years, which is the maximum lifespan so far recorded in Spain. We have contributed the results of our research to the International Database of Longevity (IDL).
\end{abstract}

\section{Introduction}

Currently, there appears to be a broad consensus among population researchers that there is no empirical evidence to support the assertion that we have reached the highest limits of human life (Wilmoth, 1997; Jeune and Vaupel, 1995; Vaupel et al., 1998; Wilmoth and Robine, 2001). On the other hand, researchers largely agree that few mortality models fit better than Gompertz's law (Thatcher, Kannisto, and Vaupel, 1998). These two main subjects are key issues, and are the main focus of our future research. Within this framework, we can sub- 
mit preliminary results of our research regarding the following specific objective.

The characteristics of centenarians, semisupercentenarians, and supercentenarians - including their mortality evolution, their appearance, and their chronology and intensity according to ages - have yet to be well established. There is a certain mythology around living to the age of 100 or beyond. This mentality, combined with the late establishment of civil registers in several countries, led to a lack of data for the late 19th and 20th centuries, both for living and dead people at extreme ages. To gain a better understanding of the mortality characteristics of the oldest-old, it is therefore imperative to screen the existing data, especially for the most recent cases. We start by filtering out cases in which the alleged age at death is clearly exaggerated or wrong. Our main goal is to validate the Spanish data.

We must take into account that this detailed and meticulous verification task forms the basis for later methodological advances. This is because, in each and every development or readjustment of a demographic model, we must use filtered and observed data as our starting point. First, we provide a general overview of death and mortality at extreme ages in Spain, which allows us to place the mortality of centenarians and semisupercentenarians in the global context of rising longevity.

As death rates fall and people live longer, the frequency distribution of ages at death has moved to the right. This distribution has become more compressed around a displacing mode (Kannisto, 2000; 2001); furthermore, it seems that the whole mortality distribution is shifting to the right (Bongaarts and Feneey, 2002). Therefore, the exchange between compression and shifting mortality forms the background for the emergence of centenarians.

\section{Data and sources}

Our main sources, and the most vital ones for the purposes of age verification, are the municipal Civil Registers. The Official Deaths Register was used as an intermediate source that enabled us to compile a list of potential supercentenarians. The Official Deaths Register is maintained by both the Spanish Statistics Institute (INE) and the Ministry of Justice, and is stored as the National Death Index at the Ministry of Health. We will describe this register in detail later. We have also used two additional databases that help us place Spanish mortality in a general context. 
The original source of death data is, for the whole period, the National Statistics Institute of Spain (INE), either via the Human Mortality Database (HMD, www.mortality.org) (Glei et al., 2006) for the periods of 1908-1946/5 and for 1999 onwards; or via Väinö Kannisto's estimates for the 1947-1998 period. The Kannisto-Thatcher Database on Longevity (KTDB) provides estimates for each simple age, and for each chronological year. In calculating these estimates, the KTDB relies on two main methods: until 2004, the extinct/almost extinct cohort method is used for every age, while from 2005 onwards, the survival ratio method is used for ages over 90 (Thatcher, Kannisto, and Andreev, 2001).

The KTDB computes the number of deaths at age $\mathrm{x}$ by summing up the death counts included in the Lexis triangles corresponding to each cohort. Deaths at ages $(\mathrm{x} 1, \mathrm{x} 2)$ for a year $\mathrm{y}$ for an aggregated population are calculated by:

$$
D_{X_{1}, X_{2}}(y)=\sum_{X-X_{1}}^{X_{2}}(D(x, y, y-x)+D(x, y, y-x-1))
$$

The whole methodology can be found online at the Max Planck Institute for Demographic Research website (http://www .demogr .mpg. de).

The KTDB was used for the first step in the analysis of the emergence of Spanish centenarians. Managed and maintained by the Max Planck Institute for Demographic Research, this database is an essential tool for any demographic research on longevity, and is especially useful for comparative analysis. The KTDB offers temporary yearly series of deaths and populations from 1908 to 2004, the last year available prior to publication of this book. We can, therefore, draw a picture of Spanish longevity throughout the 20th century based on these databases.

\section{Emergence of the deaths of centenarians and supercentenarians}

\subsection{Deaths of oldest-old people}

Before discussing in detail the results of our verification efforts, we wish to provide a general overview of our principal subject. We will focus on the process of the emergence of centenarians, semisupercentenarians, and supercentenarians by studying the deaths of those who have reached the ages of 100,105 , and 110 or more. 
We use data drawn from the KTDB because this database offers a wider short-term outlook than the figures provided by the INE. The analysis of the period 1965-2004 shows that the number of deaths among centenarians grew continuously. This tendency occurred parallel to an increase in age of death at advanced ages. The new century arrived with a second surge in centenarians' deaths (see Figures 1 and 2 ). The change in the figures is dramatic: in 1973, there were 318 deaths, of whom 45 were men and 273 were women; while in 2004, there were 2,323 deaths among centenarians, of whom 500 were men and 1,823 were women. Figure 3 illustrates this trend, showing that, while the number of deaths among people over 100 years old rose throughout the 20th century, this increase did not become exponential until the 1970s.

A very similar trend can be seen in the deaths of semisupercentenarians. We observe the same tendencies throughout the period studied, though obviously with much more modest figures. The smaller number of supercentenarian deaths allows us to verify each one of the cases, a task we address later.

The emergence of centenarians and semisupercentenarians shows a similar profile in different European countries, though Spain experienced a clear delay in the emergence of centenarians when compared to countries like France, where it occurred in the 1960s or even earlier (Robine and Caselli, 2005). In fact, when we use the same source, the KTDB, to compare trends in different countries, we can see that the emergence of centenarians in Spain, which took place during the early 1970 s, is very close to the trends found in Germany and Italy ${ }^{3}$.

The investigation of deaths at extreme ages may, therefore, also enable us to better understand a remarkable historic phenomenon: the emergence of a new group of people, which is growing both in size, and in terms of the highest age reached. There is an increase in rates of survival, with more and more people celebrating 100th and 105th birthdays every year.

\subsection{Mortality among centenarians, a declining issue}

Parallel to the emergence of oldest-old people, there has been a drop in the adult mortality rate, especially among the more aged groups. Longevity among the Spanish population has reached a high level in comparison to other countries. In Figures 3 and 4, we can see changes in

\footnotetext{
${ }^{3}$ In those years when we observe the emergence of Spanish centenarians, there is no noticeable change in the registration system that might account for the observed trend.
} 


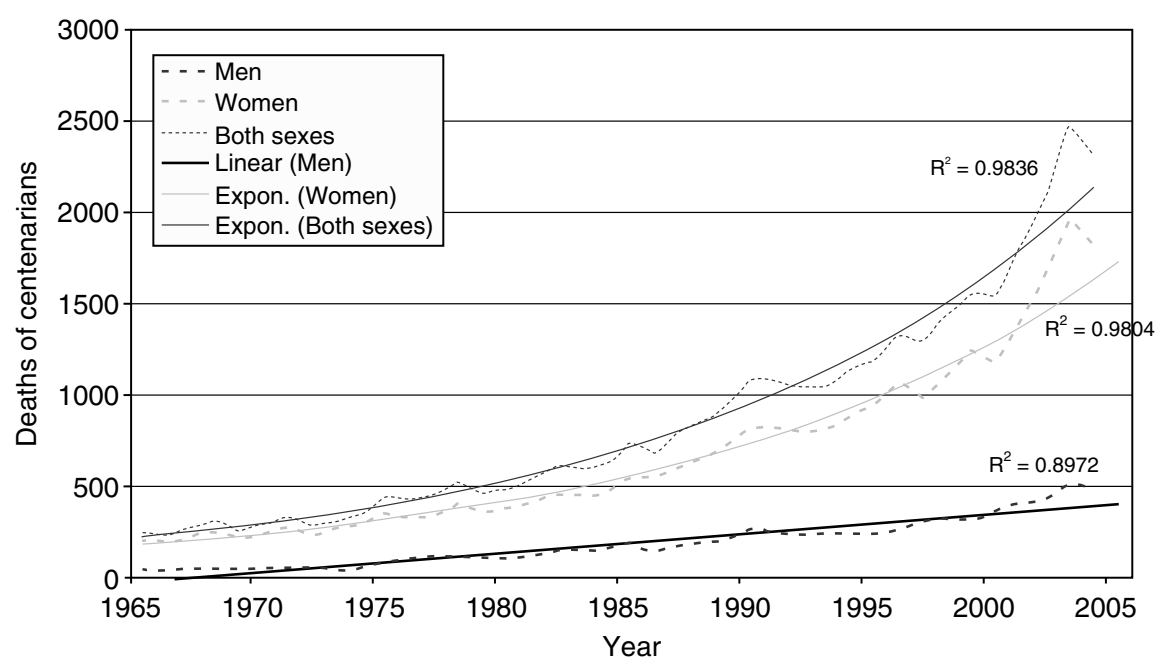

Fig. 1. Deaths of centenarians, by sex. Spain, 1965-2004

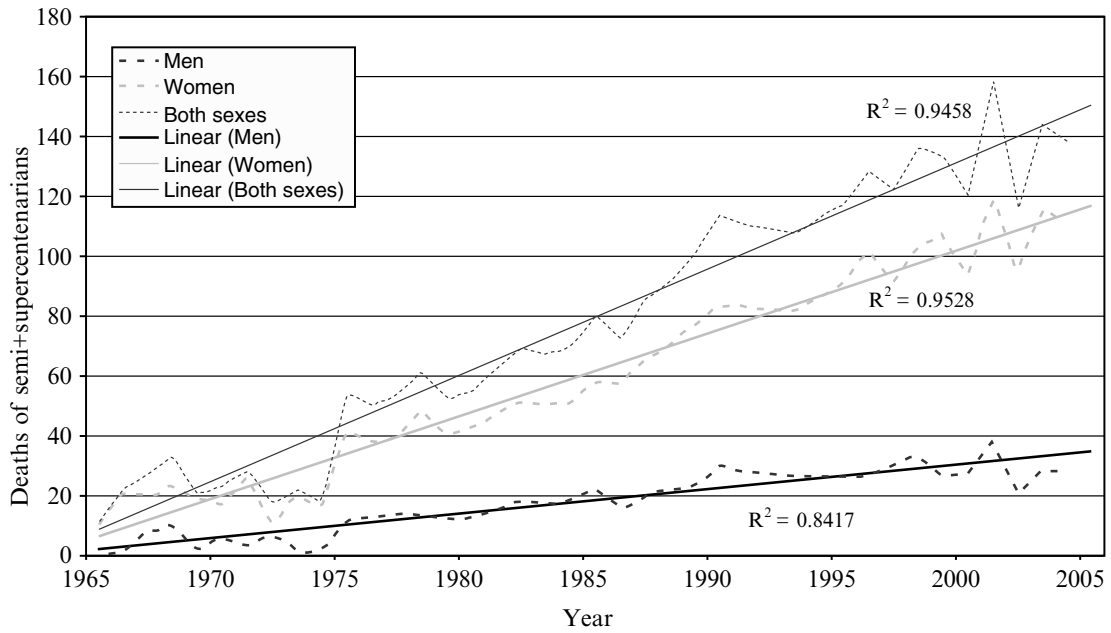

Fig. 2. Deaths of semisupercentenarians (ages 105+), by sex. Spain, 19652004 
the probability of death among centenarians and semisupercentenarians for each year during the 1908-2006 period. In centenarians, the decrease in the probability of dying is obvious.

Mortality among people who have reached the age of 100 shows big yearly fluctuations. Furthermore, we can distinguish two different periods. During the first period, from 1908 to 1968-1973, mortality clearly increases. We can see the effects of the Civil War (1936-1939) and the immediate postwar period (1940-1942). A partial explanation for the increase seen in the first half of the 20th century may lie in the constant improvement in data quality, although it is difficult to state with total certainty that this is the case ${ }^{4}$. There was an improvement in the census over this period, as increasing attention was paid to the quality of data for very advanced ages, and the data was offered at a higher desegregation level. After 1968-1973, the probability of death leveled off, and even decreased slightly, presenting less fluctuation. This new trend correlates with the fact that, since then, the census and the registers have been extremely reliable.

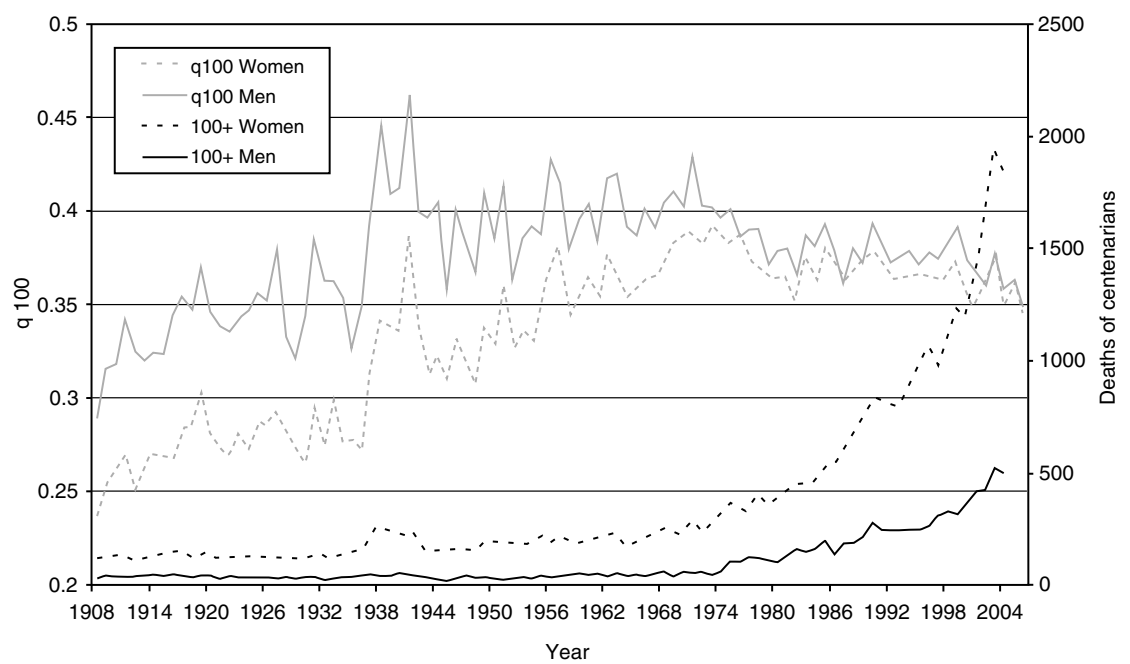

Fig. 3. Deaths of centenarians and $\mathrm{q}_{100}$, by sex. Spain, 1908-2004

\footnotetext{
${ }^{4}$ Most likely, there was a problem of overestimation in both the centenarian population and in centenarian deaths that was progressively adjusted throughout the period under study. Nevertheless, there is need to study why the statistical artifacts of Vital Registers regarding deaths were improved later than the Census.
} 


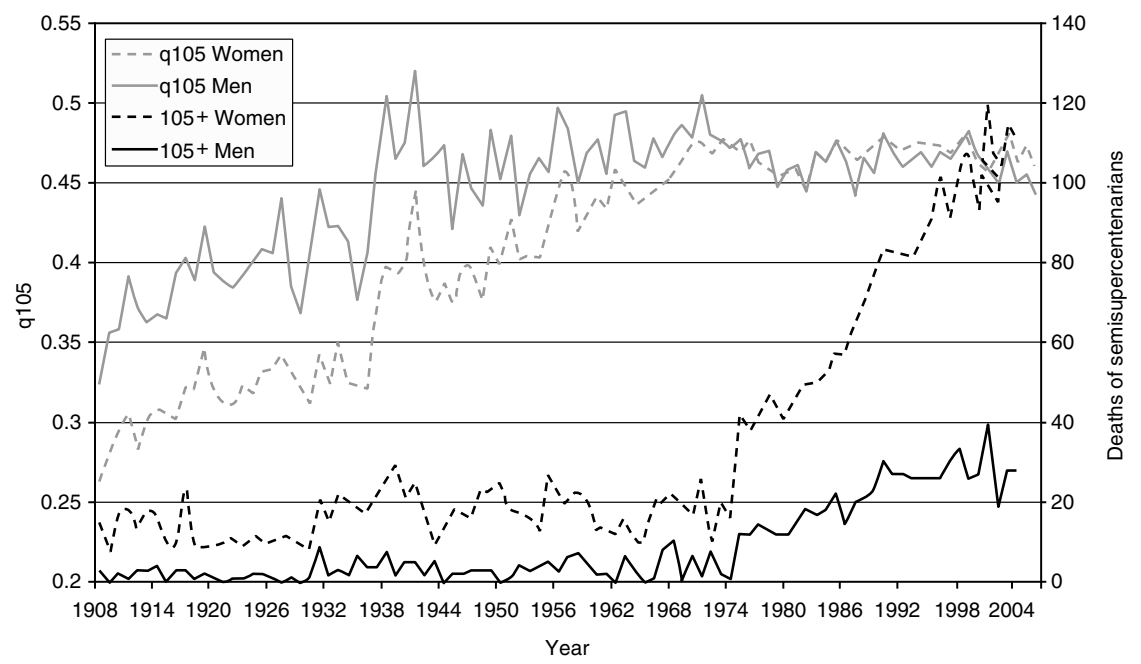

Fig. 4. Deaths of semisupercentenarians and $\mathrm{q}_{105}$, by sex. Spain, 1908-2004

Among people who have reached the age of 105, fluctuations and irregularities are even greater. The trend in the probability of death at age 105 is irregular in both sexes, but has been declining in recent years. Among men aged 105, the intensity of mortality has decreased gradually. Nevertheless, the gender gap in the probability of death has been smoothed out, and the clear differences seen throughout the lifespans of men and women seem to diminish. Due to the limited number of cases, the irregularities observed among semisupercentenarians are even greater among supercentenarians. Until a more complete database for extreme longevity cases, and, specifically for supercentenarians, is compiled, we may want to wait before describing any differential trend by sex at ages 105 and above.

\section{Verification of Spanish supercentenarians}

As part of this study, we have carried out age validation for Spanish people who had reached the age of 110 or above at the time of their death, each of which occurred between January 1987 and April 2007. We have only included people who were born and died on Spanish territory, due to the difficulties involved in verifying the life trajectories of those born abroad. 


\subsection{Methodology and process of validation}

We begin this part of the chapter with a discussion of the Spanish sources for verifying ages and their characteristics. We then go on to describe the structure of the Civil Register, our methodology, and, finally, the different stages of the process used to verify Spanish supercentenarians.

In Spain, compiling a list of living persons who are 110 years old or older is not a simple matter. There is no register, center, or institute that provides a list of names of possible supercentenarians that would allow us to locate them and investigate their lives, as well as, ultimately, their deaths. Due to the characteristics of the Spanish register and census systems, and to the privacy provisions of the Data Protection Law, it is not easy to establish the existence of people with very high ages until after they died.

The degree of access to individualized mortality data is very different in each country. Some countries allow complete public access to the data, but other countries, like Spain, place restrictions on access to some data, thus hampering research. With some restrictions, we can, however, obtain data on deaths from the state.

All the deaths that are registered in Spain are gathered in an information system called the National Death Index (IND). The IND is regulated by two laws: Order of 25 February 2000 (Boletín Oficial del Estado (BOE), 54, 3 March 2000) and the 2005 modification (Order PRE/2131/2005, 29 June, BOE n. 159, 5 July 2005). This database was launched in 2000, but includes data from 1987 to date. (The IND is compiled as follows: the data from the civil registers (Ministry of Justice) are collected by the National Statistics Institute (INE) (Ministry of Economy). INE provides these data to the Institute of Sanitary Information of the Quality Agency of the National Health System (Ministry of Health). This latter institute compiles and maintains the IND.) This is a restricted data system, and is open only to state institutions, such as research centers and health agencies. The data cannot be accessed by private institutions. Public institutions can obtain both aggregated and individualized data. To gain access to both types of data, the applicant must have the support of an eligible institution. In our case, we obtained permission to access the data from the state administration in March 2007. This was part of a collaboration agreement between the Ministry of Justice and the National University of Distance Education within the scope of our research project. Without this agreement, our research would have been impossible. 
Each individual file in the register includes the following information: names and surnames of the deceased; place of birth; last residence; place of death (codified); year, month, and day of both birth and death; volume, book and page where the death is registered; identity card number $^{5}$; sex; civil status; and nationality. The IND has several limitations, including a lack of information about the cause of death. This information can, however, be obtained within the official agreement mentioned above. Because, as previously mentioned, information is only available since 1987, we were only able to verify the ages of supercentenarians who died between January 1987 and April 2007, the last date available when we started this research.

From these data, we developed different stages. The first stage was to refine the data. In Spain, about 400,000 deaths occur each year and, evidently, only very few of them are entered in our list of possible supercentenarians. First, we calculated the difference in years between the date of death and the date of birth to get a list of people who could have reached an age of at least 110. We thus obtained a list of possible supercentenarians. Our first list consisted of 191 potential supercentenarians who had died in the period from January 1987 to April 2007. Using this list, we could start the process of validating the ages of each person who may have lived beyond his or her 110th birthday.

In Spain, the registration of vital events is the responsibility of state governments. Each town has its own municipal Civil Register, where people must register births, marriages, and deaths. There is also a central Civil Register, which is responsible for coordinating the municipal registers. Otherwise, Civil Registers function independently. It is important to point out that Spain has 8,108 towns, and that each municipality has its own Civil Register, regardless of the population size. These registers began operating in 1870 . As we have potential supercentenarians since 1987, the temporal difference between the establishment of the Civil Registers and our first data is 117 years, enough time to guarantee that every possible supercentenarian was registered at birth after 1870. Every birth and every death is registered in the municipal Civil Register of the town where the person was born or died. We had to search both birth and death certificates for each potential person who had exceeded the 110-year mark.

We used the following procedures for validating the ages of these people. Although the starting data offer us some guarantees due to their relevance and official nature, it is essential to check each and every

${ }^{5}$ This variable is only available from 1996. 
variable. As mentioned previously, the variables that must be checked in the course of the verification process are the following: date and place of birth, date and place of death, and, of course, the name of each potential supercentenarian. This means that two sets of information are required, and that there are two stages in the validation of each case. In the first phase, a communication process is established with the appropriate Civil Registers, including the town of birth and the town of death, so that an official request for the vital records of both of birth and death can be made for each potential supercentenarian. This is a difficult process that includes sending a letter or making a phone call to the officials responsible for the Civil Registers, usually judges, justices of the peace, or town clerks. There are usually no problems with death certificates, but there are a lot difficulties with birth certificates, as we will see later. Civil Registers are obliged to provide certified copies of the certificates free of charge (Law 25/1986, 24 December, BOE, n. 313, 31 December 1986). It is important to get a legal signature of each certificate. We thus guarantee that the documents are official, and that an exhaustive and reliable verification of age has taken place.

Once the documents have been obtained, we enter the second phase, which consists of a comparison of the certified forms received. These documents provide administrative proof of the start and the end of the person's life. In this way, we can define the real age of the people on the list, eliminating false cases of supercentenarians. In carrying out the verification, we have used the technique of matching vital records linked to each of the deaths. The first step is to check the age of the deceased. To do this, we have to certify the exact dates of birth and death of each potential supercentenarian, and then calculate the age. As for the names and surnames, it is important to note that Spanish people have two surnames: the first surname is usually the father's, and the second is the mother's. We can thus check the identity of the deceased against both names. If we want to be even more accurate, we can compare the grandparents' surnames, which are included in the birth certificate along with the parents' names. Finally, both the birth and the death certificate contain the names of the parents. It is then possible to compare them both, lending yet another degree of exhaustiveness to the validation. Therefore, we validate both the age and the identity of the person, first through the dates of birth and death, and second thanks to the peculiar feature of the structure of Spanish surnames. This is meticulous but necessary work, since the quality of the verification depends on how it is carried out. Especially in cases where the line between being or not being a supercentenarian 
is very thin, the procedures followed in the verification process must be thorough.

This detailed task of filtering does not always eliminate all the errors and inconsistencies in the list of dead people provided by the INE. Such errors are basically caused by the cumulative bias that occurs when family members or other acquaintances fill out forms, as well as in the transfer of data to the INE's computer systems. The main problem, as we have just stated, is the sum total of the cumulative bias that this database presents. Once we have the records, other kinds of bias appear: inconsistencies in dates of birth or death between the INE's data and the actual dates (e.g., a transposition of figures for the years, or registered dates of birth that are later than those included in the death records), different places of birth or death, or incorrect names or surnames (e.g., transposition of letters, and, less frequently, a mixup in the order of the two family names). Various means of correcting these errors are available, but there is one problem that is practically impossible to solve: missing entries in the Civil Register. A similar problem stems from the burning and destruction of registers during the Civil War. When these types of problems appear, we are usually dealing with lost cases.

\subsection{Structure of the validated supercentenarians and their geographic distribution in Spain}

Twenty-eight Spanish supercentenarians have been entered into the International Database on Longevity (IDL). These people had reached the age of at least 110 during the period 1987-2007, and they were deceased as of April 2007. We have included the records that certify the dates of birth and death of the supercentenarians, which serve to verify that they lived to the age of 110 and beyond.

As mentioned previously, we started with a list of 191 potential supercentenarians who may have reached age 110 between January 1987 and April 2007. As a result of this verification process, which is ongoing, the number of people whose ages have been verified is 104, but the number of real supercentenarians has been reduced to 28 (see Figure 5 ). Only one person out of every seven of the potential supercentenarians has been verified as such. The remaining 76 people whose ages were verified were not found to be supercentenarians: four were semisupercentenarians, 24 were between 100 and 104 years old, and 48 were less than 100 years old. The ages of the other 87 potential supercentenarians could not be validated, as 61 could not be found in the Civil Registers, and there were no responses for the other 26 people. But, 
as the verification is still in progress, new cases of supercentenarians could be announced in the near future.

In Figure 6, we can see that there are huge differences between our verification data, the estimations of the KTDB, and the counts of the INE. The number of potential supercentenarians counted by the INE differs greatly from both the KTDB's estimates and the number validated by this research team. The INE offers constant numeric exaggerations, while the KTDB has the same bias, though it is less noticeable. From 1987 until 2006, the INE counted 191 potential supercentenarians among the deceased, while the KTDB arrived at a figure of 70 until 2004. In any case, the differences between the estimations of the KTDB and our own data will probably be smaller when our validation data process is completed ${ }^{6}$.

So far, however, we have verified that there were 28 supercentenarians living in Spain between January 1987 and April 2007. Table 1 shows the distribution of supercentenarians by year of death and sex. There are three females for every male. We can see a distribution by age at death and sex in Table 2.

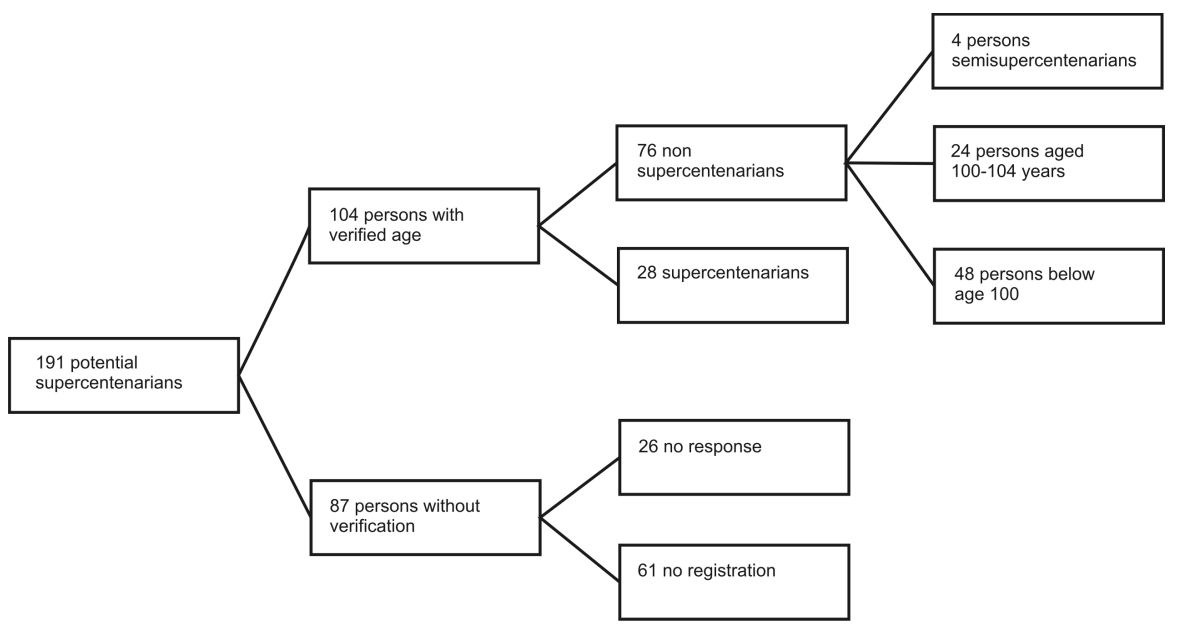

Fig. 5. Process of validation of supercentenarians. 1987-April 2007

Of the cases we investigated, we found 14 people (10 women and four men) who had reached age 110, eight who lived to age 111 (seven women

\footnotetext{
${ }^{6}$ Nevertheless, the differences by sex between KTDB estimations and our own verified data could represent an overestimation in that database of male deaths, rather than an adjustment for female deaths.
} 


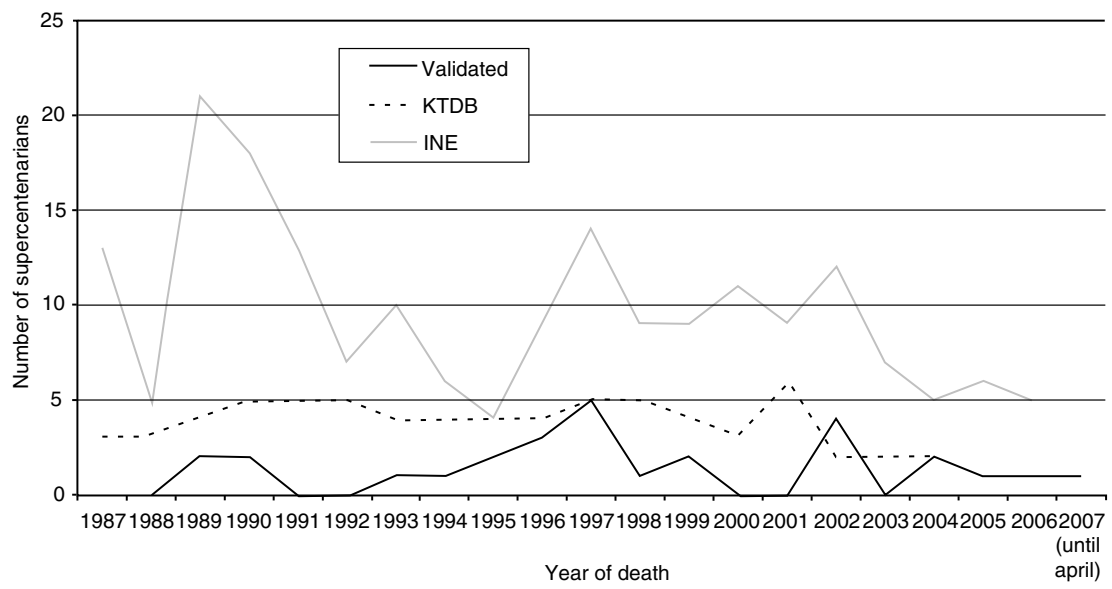

Fig. 6. Comparison of the number of supercentenarians according to different sources. National Death Index (INE), KTDB, and validated. 1987-April 2007

and one man), two who were 112 years old (one woman and one man), one woman of 113, and three people who had celebrated their 114th birthdays (two women and one man). As in other countries, younger ages make up the majority of the cases (Meslé, Vallin, and Robine, 2000). The feminization of the supercentenarian population is clear, as three out of four of these oldest-old people are women (see Table 2 and Figure 7). We should, however, point out that the number of Spanish supercentenarians does not appear to be increasing significantly over time.

Table 1. Distribution of supercentenarians by year of death and sex

\begin{tabular}{cccc} 
Year & Both sexes & Male & Female \\
\hline $1987-1990$ & 4 & 3 & 1 \\
$1991-1994$ & 2 & 1 & 1 \\
$1995-1998$ & 11 & 1 & 10 \\
1999-2002 & 6 & 1 & 5 \\
2003-April 2007 & 5 & 1 & 4 \\
Total & 28 & 7 & 21 \\
\hline
\end{tabular}


Table 2. Distribution of supercentenarians by age at death and sex

\begin{tabular}{|c|c|c|c|c|c|c|c|c|}
\hline \multirow[b]{2}{*}{ Age at death } & \multicolumn{3}{|c|}{ Supercentenarians } & \multicolumn{3}{|c|}{$\begin{array}{l}\% \text { by sex and } \\
\text { age regarding } \\
\text { total of } \mathrm{SC}\end{array}$} & \multicolumn{2}{|c|}{$\begin{array}{l}\% \text { by sex and } \\
\text { age regarding } \\
\text { total of age }\end{array}$} \\
\hline & Total & Men & Women & Total & Men & Women & Total Men & Women \\
\hline 114 & 3 & 1 & 2 & 10.7 & 3.6 & 7.1 & $100.0 \quad 33.3$ & 66.7 \\
\hline 113 & 1 & 0 & 1 & 3.6 & 0.0 & 3.6 & $100.0 \quad 0.0$ & 100.0 \\
\hline 112 & 2 & 1 & 1 & 7.1 & 3.6 & 3.6 & 100.050 .0 & 50.0 \\
\hline 111 & 8 & 1 & 7 & 28.6 & 3.6 & 25.0 & 100.012 .5 & 87.5 \\
\hline 110 & 14 & 4 & 10 & 50.0 & 14.3 & 35.7 & 100.028 .6 & 71.4 \\
\hline Total & 28 & 7 & 21 & 100.0 & 25.0 & 75.0 & $100.0 \quad 25.0$ & 75.0 \\
\hline
\end{tabular}

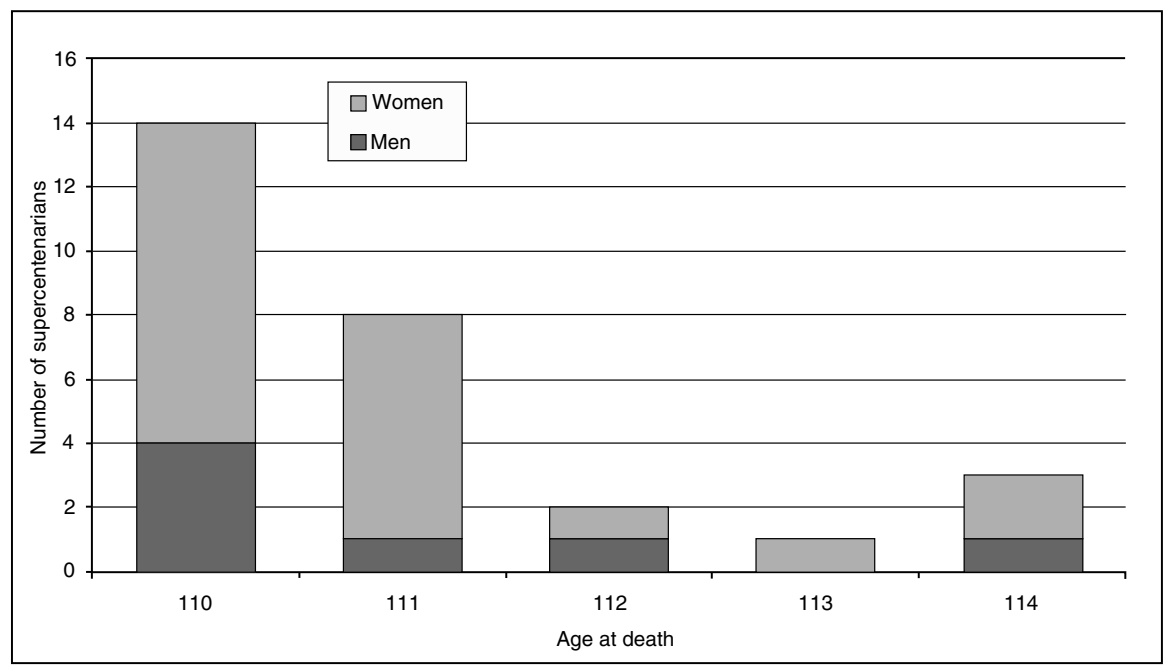

Fig. 7. Feminization of the supercentenarians: number by age and sex

The geographical distribution is shown in Table 3. Although it is still too early to establish an accurate geography of the oldest-old in Spain, we can already distinguish two zones: the North (Castile and León, Galicia, Navarre and Catalonia) and the South (Andalusia and Murcia). Furthermore, there are two regions that must be clearly differentiated from the others: Andalusia and Castile and León, which account for more than half of the supercentenarians verified, both at birth and death.

There is no relationship between the population size of the regions or provinces, and the number of supercentenarians. For example, Palencia is a small province of Castile and León with fewer than 180,000 
inhabitants, but four verified supercentenarians were born there. While several supercentenarians died in Spain's most important and populous cities, Madrid and Barcelona, none were born there. This can be attributed to the internal migration from rural to urban zones that occurred during the 20th century.

Table 3. Geographical distribution of the supercentenarians

\begin{tabular}{lc} 
Place of birth & Number \\
\hline North & 18 \\
South & 10 \\
Andalucía \& Castilla+León & 16 \\
Other regions & 12 \\
\hline Place of death & \\
\hline North & 18 \\
South & 10 \\
Andalucía \& Castilla+León & 15 \\
Other regions & 13 \\
\hline Total & 28 \\
\hline
\end{tabular}

In Table 4, we can see the tabulation of all the supercentenarians who have been verified in Spain. They are arranged by age in years and in days, and each supercentenarian is also identified by sex, region of death, and region of birth. The certified documents include the names of the municipalities of birth and death for each individual case, but their publication is forbidden by law.

As we are continuing the process of verification, we may discover that the number of supercentenarians for the period studied exceeds 28. It is also quite probable that there are other supercentenarians outside of the scope of our research, but it is impossible to know at this point whether this is the case. Conducting this research project has been a long and arduous process, requiring us to employ exacting methods to achieve the highest degree of accuracy in the validation of the ages. As these efforts continue, we may be able to add some new cases to the IDL.

\section{The emergence of oldest-old people}

In just 31 years, the number of people aged 100 and older multiplied by six. Despite the fluctuations that took place in some of those years, the general trend represents an unprecedented increase. An additional 


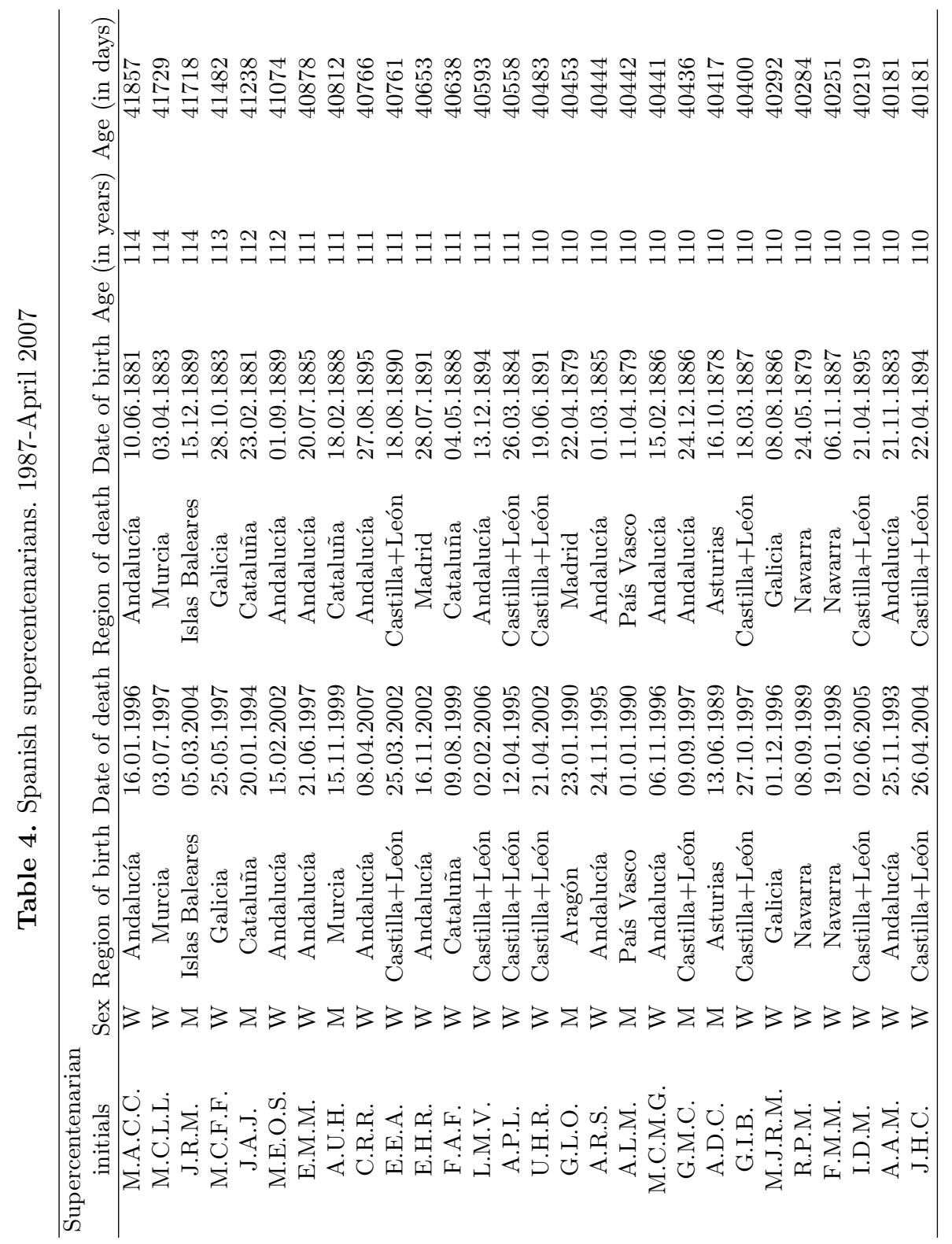


qualitative and quantitative jump occurred with the arrival of the new millennium, thus increasing the likelihood that even more people will reach age 100 or higher in the coming years.

\subsection{A new maximum for the Spanish lifespan: The present}

The main objective of the analysis of supercentenarians is to improve our knowledge about human longevity. That is why studies of this type are mainly based on the deaths of people who have reached extreme ages. There is another reason for this methodology, at least in the Spanish case. Due to the characteristics of the Spanish register and census systems, and to the constraints placed on researchers by the Data Protection Law, it is not easy to identify the individuals who are alive at a very old age. It is easier to validate the data and documents after death, but some important limitations remain due to privacy protection laws.

In the course of the verification process, we have identified the person who represents the maximum for the Spanish lifespan: a 114year-old Andalusian woman called M.A.C.C. We have verified that this woman was born in Andalusia in 1881, and died in the same place more than 114 years later; or, more precisely, after 41,857 days of life. We hope that this new discovery contributes to the discussion of whether there are limits to the human lifespan. As can be seen in Table 4, M.A.C.C. died at a slightly higher age than M.C.L.L., a woman who died in 1997, and J.R.M., a man who died in 2004.

\subsection{The potential maximum Spanish lifespan: Who are the future record holders?}

If we consider the changes that took place among the Spanish population in the 20th century, it is possible to add another nuance to the emergence of the living centenarians. The changes in the numbers of people aged 100 and older per million inhabitants are remarkable. Whereas in 1950, there were 20.85100 -year-olds for every million inhabitants (5.62 men and 35.08 women), in 2004, after a growth in population of more than 15 million, this same figure reached 160.01 centenarians per million inhabitants (67.61 men and 249.77 women). Since then, the number has increased by an additional 140 people for every one million inhabitants; that is, the number has multiplied by eight. If we take into account gender, the number of male centenarians has multiplied by 12 , and the number of female 100-year-olds by 7.1 . Although the number of centenarians per million is much higher among women, the increase among men is greater. 
Throughout the 1955-2003 period, there were almost 362 women for every 100 men who reached age 100, a ratio of almost four females to one male. There was also an increase in the number of people aged 105 and older. The proportion of semisupercentenarians compared to the whole of the population is more modest than the proportion of centenarians, although not less representative. In 1950, the number of people aged 105 or older was 1.46 for every one million inhabitants (0.37 men and 2.49 women), while in 2006, it had increased to 7.50 per million (3.15 men and 11.73 women). Over the course of these 56 years, the number has multiplied by more than five ( 8.5 for men, 4.7 for women). Differentials by sex have become a key issue for centenarian and semisupercentenarian research.

If we compare data from different European countries drawn from the same source, the KTDB, we find that the ratio of women in the centenarian and semisupercentenarian populations in Spain is unusually low. While the ratio of women among Spanish centenarians is 3.62 females for one male, the corresponding ratios are 4.12 in Italy and 6.46 in France. A similar trend can be seen among semisupercentenarians. Thus, the increase in the number of male centenarians in Spain is, in fact, much higher than in neighboring countries. One possible explanation for this trend might be related to a differential adjustment by sex in the KTDB's estimations. On the other hand, we should also consider the possibility that the average time lapse between birth and registration was different depending on the sex of the newborn ${ }^{7}$. Within the social context of small villages in the countryside of Southern Europe, and taking into account the well established differences in the value placed on girls and boys among these generations, we might expect to see a higher rate of error in the registration of female births. These considerations could also partly explain why Southern Europe has always had a higher ratio of men to women than Northern and Central European countries.

This increase in the number of centenarians, semisupercentenarians, and supercentenarians suggests the possibility that, among the supercentenarians today, there might be cases that exceed the known maximum lifespan, or that more people are at least getting closer to exceeding it. Among the individuals who have the potential to reach a new maximum lifespan in the future, M.F.F., who resides in the North of Spain, is a good example. Currently 113 years old, M.F.F. has lived

\footnotetext{
7 There are cases in small villages in which two newborns (brothers or sisters) were registered at the time of the second birth, thus creating a registration error in the birth date of the first child.
} 
in two different countries, and her life spans three centuries. She is, at the time of writing, the known seventh-oldest validated living person in the world.

\section{Discussion}

The chronology of the appearance of centenarians and semisupercentenarians in Spain is in line with the more relevant period of the process of exchange between compression and the shifting of mortality at advanced ages. However, it is early to suppose that the evolution of the mortality of supercentenarians will follow the same pattern as that of the younger age groups in the near future. Given the irregularity observed in supercentenarian trends during the last decades, due in large part to the small number of cases studied, it seems imperative to continue this analysis, taking into account later periods.

What is the maximum lifespan human beings will reach? Which is the most accurate mathematical model for mortality at advanced ages? These are some questions that we posed in the introduction to this paper as relevant subjects for contemporary research. In order to answer these questions, and to develop models that allow us to do so, it is imperative to verify both old and current data of supercentenarians. This is an indispensable condition for the estimation of their mortality and the improvement of population projections that involve advanced ages. We have overcome the limited volume of Spanish verified data for the period studied in this chapter, and intend to research other periods. With more recent generations included, we will be able to verify the deceleration of increasing age-related deaths at very advanced ages (Horiuchi and Wilmoth, 1998; Vaupel et al., 1998). The other essential means of deepening our understanding of the process is through contributing to the IDL, both in terms of verified cases and in the methodology used in validation. Through the IDL, we will able to identify aggregates of verified data from different countries and generations that allow new research possibilities for the scientific community (Robine and Vaupel, 2002). Up until the present, our main contribution to the IDL has consisted of carrying out the verification of the corresponding oldest-old population in Spain.

It is only by joint, international efforts that we will be able to determine whether the appearance of supercentenarians is, in fact, the tip of the iceberg of a new trend that is clearly noticeable among centenarians. For the moment, however, our main focus is on checking the quality 
of our data, so that we can help to shed light on the displacement of Kannisto's invisible wall.

\section{Acknowledgements}

This study was financed by Grant SEG2006-10972 from the Spanish Ministry of Science and Innovation. We would like to thank the Civil Registers of the municipalities for their cooperation in helping us obtain the documents needed for validation. We also wish to thank the National Institute of Statistics (INE), the Ministry of Justice, and the Ministry of Health for agreeing to allow researchers from our university access to the initial basic data used in this study. Finally, we would like to thank the supercentenarian M.F.F. and her family for making themselves available to us, thereby facilitating and enriching our work.

\section{References}

Bongaarts, J. and Feeney, G. (2002). How long do we live? Population and Development Review, 28(1):13-29.

Glei, D., Gómez-Redondo, R., Argeso A., and Canudas-Romo, V. (2006). About mortality data for Spain. Human Mortality Database. Available at www.mortality.org.

Horiuchi, S. and Wilmoth, J. R. (1998). Deceleration in the age pattern of mortality at older ages. Demography, 35(4):391-412.

Human Mortality Database (2008). University of California, Berkeley (USA), and Max Planck Institute for Demographic Research (Germany). Available at www.mortality.org or www.humanmortality.de (data downloaded in October 2008).

Jeune, B. and Vaupel, J.W. (1995). Exceptional Longevity: From Prehistory to the Present. Odense University Press.

Kannisto, V. (2000). Measuring the compression of mortality. Demographic Research, 3(6).

Kannisto, V. (2001). Mode and dispersion of the length of life. Population (An English Selection), 13(1):159-172.

Kannisto-Thatcher Database on Longevity (2008). Max Planck Institute for Demographic Research (Germany). Available at: www. demogr .mpg. de (data downloaded in October 2008).

Meslé, F., Vallin, J., and Robine, J-M. (2000). Vivre plus de 110 ans en france. Gérontologie et Société, 94:101-120.

Ministry of Health (1987-2007). National Death Index. Spain.

Robine, J-M. and Caselli, G. (2005). An unprecedented increase in the number of centenarians. Genus, LXI(1):57-82.

Robine, J-M. and Vaupel, J.W. (2002). Emergence of supercentenarians in low mortality countries. North American Actuarial Journal, 6(3):54-63. 
Thatcher, A.R., Kannisto, V., and Andreev, K. (2002). The survivor ratio method for estimating numbers at high ages. Demographic Research, 6(1). Available online at: www.demographic-research.org.

Thatcher, A.R., Kannisto, V., and Vaupel, J.W. (1998). The Force of Mortality at Ages 80 to 120. (Odense Monographs on Population Aging), volume 6. Odense. Denmark: Odense University Press.

Vaupel, J.W., Carey, J.R., Christensen, K., Johnson, T.E., Yashin, A.I., Holm, N.V., Iachine, I.A., Kannisto, V.A., Khazaeli, A., Liedo, P., Longo, V.D., Zeng, Y., Manton, K.G., and Curtsinger, J.W. (1998). Biodemographic trajectories of longevity. Science, 280(5365):855-860.

Wilmoth, J.R. (1997). In search of limits, chapter in Wachter, K. and Finch, C.E. (eds): Between Zeus and the Salmon: The Biodemography of Longevity, National Research Council. National Academy Press, Washington, D.C.

Wilmoth, J.R. (1998). The future of human longevity: A demographers' perspective. Science, 280(5362):395-397.

Wilmoth, J.R. and Robine, J.M. (2003). The world trend in maximum lifespan. Population and Development Review, 29:239-257. 